\title{
STRATEGI PENGEMBANGAN BUDIDAYA KENTANG (Solanum Tuberosum L) DI KECAMATAN NGABLAK KABUPATEN MAGELANG
}

\author{
Mahkruf Joko Purwanto, Mohd. Harisudin, Aulia Qonita \\ Program Studi Agribisnis Fakultas Pertanian, Universitas Sebelas Maret Surakarta \\ E-mail: mahkrufjokop@gmail.com
}

\begin{abstract}
This study aims to determine the cost, revenue and profit in potato cultivation in Ngablak subdistrict, analyze internal and external factors, formulate strategic alternatives, prioritize strategies that can be applied in developing in potato cultivation in the Ngablak subdistrict. The basic method of research is descriptive analysis. The research location in Ngablak subdistrict Magelang regency. The data used are primary and secondary data. Analysis of the data were used: (1) Cost, Revenue, Income and Profit, (2) Analysis of Internal Factor Evaluation, (3) External Factor Evaluation, (4) SWOT Analysis, (5) QSPM. The Results showed, the cost potato cultivationis Rp.11,413,271.00, revenue is Rp.18,631,117.00. income to Rp.7,217,846.00 and the profit received Rp.4,827,071.00. Internal Factor Evaluation (IFE) showed that there are four strengths and six weaknesses. External Factor Evaluation (EFE) shows that there are six opportunities and three threats. SWOT Analysis generate alternative strategies that can be applied is to maintain the quality and increase the quantity of potato cultivation with agricultural intensification, maximizing land for planting potato through monoculture cropping systems and crop rotation as well as utilizing existing technology and marketing cooperation relationship with more than a middleman. QSPM analysis showed that the priority of strategy can be applied is to maintain the quality and increasing the quantity of potato cultivation with agricultural intensification.
\end{abstract}

Keywords: potato cultivation, profit, SWOT, QSPM

Abstrak : Penelitian ini bertujuan untuk mengetahui biaya, penerimaan dan keuntungan dalam budidaya kentang di Kecamatan Ngablak, menganalisa faktor internal dan eksternal, merumuskan alternative strategi, menentukan prioritas strategi yang dapat diterapkan dalam mengembangkan budidaya kentang di Kecamatan Ngablak. Metode dasar penelitian adalah deskriptif analisis. Lokasi penelitian yaitu Kecamatan Ngablak Kabupaten Magelang. Data yang digunakan adalah data primer dan sekunder. Analisis data yang digunakan adalah (1) Analisis Biaya, Penerimaan, Pendapatan dan Keuntungan, (2) Analisis Internal Factor Evaluation, (3) External Factor Evaluation, (4) Analisis SWOT, (5) QSPM. Hasil penelitian menunjukkan, biaya budidaya kentang sebesar Rp.11.413.271,00, Penerimaan sebesar Rp.18.631.117,00. Pendapatan sebesar Rp 7.217.846,00 dan keuntungan yang diterima sebesar Rp.4.827.071,00. Internal Factor Evaluation (IFE) menunjukkan bahwa terdapat empat kekuatan dan enam kelemahan. External Factor Evaluation (EFE) menunjukkan bahwa terdapat enam peluang dan tiga ancaman. Analisis SWOT menghasilkan alternatif strategi yang dapat diterapkan yaitu mempertahankan kualitas dan meningkatkan kuantitas hasil budidaya kentang dengan intensifikasi pertanian, memaksimalkan lahan penanaman kentang melalui sistem budidaya monokultur dan rotasi tanam serta memanfaatkan teknologi yang ada, dan menjalin hubungan kerjasama pemasaran dengan lebih dari satu tengkulak. Analisis QSPM menunjukkan bahwa prioritas strategi yang dapat diterapkan adalah mempertahankan kualitas dan meningkatkan kuantitas hasil budidaya kentang dengan intensifikasi pertanian.

Kata Kunci : budidaya kentang, keuntungan, SWOT, QSPM 


\section{PENDAHULUAN}

Subsektor hortikultura mempunyai peran cukup penting dan strategis, terutama dalam upaya pemenuhan ketersediaan dan kecukupan pangan serta penyediaan lapangan kerja. Menurut hasil dari Sensus Pertanian (2013:17), jumlah petani subsektor hortikultura sebesar 11.950.989 jiwa atau sekitar 12,5 persen dari total petani Indonesia yang jumlahnya sebesar 95.126.338 jiwa. Sedangkan menurut Renstra Dirjen Hortikultura (2015 : 16), tidaklah mengherankan bila kontribusi subsektor hortikultura pada Produk Domestik Bruto Tahun 2014 sebesar Rp227,47 Trilyun. Hal tersebut menunjukkan peran penting subsektor hortikultura dalam mendukung perekonomian nasional.

Tanaman kentang (Solanum Tuberosum L.) merupakan salah satu komoditas hortikultura. Daya tarik sayuran ini terletak pada umbinya yang memiliki nilai gizi tinggi, prospek pasar yang baik, dapat disimpan dalam waktu yang cukup (tidak mudah rusak) (Baihaqi et al, 2013 : 31). Menurut Khurana (2006 : 1), kentang merupakan tanaman yang dapat melengkapi kebutuhan pangan masyarakat.

Provinsi Jawa Tengah merupakan salah satu Provinsi yang berkontribusi dalam menghasilkan kentang di Indonesia. Luas panen kentang di Jawa Tengah mencapai 17.630 ha dan untuk produksi kentang mencapai 2.735.135 kwintal (BPS Jawa Tengah,2013 : 15). Salah satu wilayah di Jawa Tengah yang merupakan penghasil kentang adalah Kabupaten Magelang. Kabupaten Magelang merupakan salah satu daerah yang memiliki potensi untuk pengembangan kentang. Menurut Badan Pusat Statistik Kabupaten Magelang (2014), produksi kentang mencapai 43.552 kwintal. Daerah penghasil kentang di Kabupaten Magelang adalah di Kecamatan Kajoran, Kaliangkrik, Pakis, dan Ngablak.

Tabel 1 menunjukan bahwa Kecamatan Ngablak merupakan salah satu daerah penghasil kentang di Kabupaten Magelang. Kecamatan Ngablak memiliki luas panen 72 ha, produksi 13.995 kwintal dengan rata-rata produksi 194,37 $\mathrm{kwintal} / \mathrm{ha}$ dan wilayah dengan ketinggian $1.378 \mathrm{~m}$ dpl. Salah satu kelebihan Kecamatan Ngablak adalah memiliki ketinggian $1.378 \mathrm{~m}$ dpl. Menurut Setiadi (2009 : 49), kentang dapat tumbuh subur di daerah pegunungan dengan ketinggian sekitar 500$3.000 \mathrm{~m}$ dpl. Namun, tempat yang ideal berkisar antara 1.000-1.300 mdpl. Kecamatan Ngablak memiliki rata-rata produksi dibawah Kecamatan Pakis (214,74 kwintal/ha) sehingga budidaya kentang di Kecamatan Ngablak belum dapat memproduksi kentang secara optimal, dilihat rata-rata produksi yang masih tertinggal dengan Kecamatan Pakis.

Selain itu, budidaya kentang di Kecamatan Ngablak belum dapat memaksimalkan potensi ketinggian wilayah yang merupakan syarat ideal untuk penanaman kentang.Tujuan penelitian ini untuk mengetahui besarnya biaya, penerimaan, dan pendapatan. Mengetahui kondisi faktor internal dan faktor eksternal. Merumuskan alternatif strategi dan prioritas strategi.

\section{METODE PENELITIAN}

Metode penelitian yang digunakan adalah metode deskriptif analitis. Metode yang memusatkan diri pada pemecahan masalah yang ada di masa sekarang, dilakukan pengumpulan atau penyusunan dataserta dianalisa dan interprestasikan sehingga mudah dipahami (Surakhmad, 2006 : 139).

Tabel 1. Rekapitulasi Luas Panen, Produksi Kentang dan Potensi Ketinggian Wilayah Kecamatan di Kabupaten Magelang

\begin{tabular}{rlrrrr}
\hline No & Kecamatan & Panen(ha) & Produksi(kw) & Rata $^{2}(\mathrm{kw} / \mathrm{ha})$ & Ketinggian $(\mathrm{m} \mathrm{dpl})$ \\
\hline 1 & Kajoran & 24 & 2.560 & 106,66 & 578 \\
2 & Kaliangkrik & 28 & 4.234 & 151,21 & 823 \\
3 & Pakis & 106 & 22.763 & 214,74 & 841 \\
4 & Ngablak & 72 & 13.995 & 194,37 & 1.378 \\
\hline
\end{tabular}

Sumber: Dinas Pertanian, Perkebunan, dan Kehutanan Kabupaten Magelang 2014 
Pemilihan lokasi penelitian dilakukan dengan metode purposive, yaitu penentuan daerah diambil secara sengaja berdasarkan pertimbangan tertentu (Singarimbun, 1995 : 155). Kecamatan Ngablak memiliki ketinggian $1.378 \mathrm{~m}$ dpl yang berpotensi untuk produksi kentang. Penelitian dilakukan pada bulan Maret sampai Juli tahun 2016.

Pengambilan sampel untuk analisis usahatani dilakukan dengan metode propotional sampling dengan memilih jumlah responden sebanyak 30 orang petani kentang pada masing-masing kelompok tani. Selain itu, untuk identifikasi faktor eksternal dan internal serta merumuskan alternatif dan prioritas strategi menggunakan key informan yang penentuan informan diambil secara purposive yaitu petugas Balai Penyuluhan Pertanian dan Kehutanan (BPPK) dan empat petani yang diambil masing-masing satu dari setiap kelompok tani.

Metode analisis data yang digunakan adalah Analisis Biaya, Penerimaan, Keuntungan, Matriks Internal Factor Evaluation dan Eksternal Factor Evaluation, SWOT model Pearce dan Robinson, serta menggunakan Quantitative Strategic Planning Matriks.

\section{HASIL DAN PEMBAHASAN}

\section{Keadaan Umum Lokasi Penelitian}

Kecamatan Ngablak merupakan salah satu kecamatan di Daerah Tingkat II Kabupaten Magelang Propinsi Jawa Tengah dengan luas wilayah $43.78 \mathrm{Km}^{2}$. Kecamatan Ngablak berada di lereng Gunung Merbabu dengan iklim sejuk dan suhu udara rata-rata berkisar $17^{\circ} \mathrm{C}$ serta memiliki curah hujan $2.147,35$ $\mathrm{mm} /$ tahun. Ketinggian rata-rata Kecamatan Ngablak berada pada $1.378 \mathrm{~m}$ dpl. Kecamatan Ngablak memiliki tanah yang bergelombang dan berjenis Andosol Coklat. Sejalan dengan Kloosterman et al (2013 : 246), kentang banyak dibudidayakan di dataran tinggi seperti di dataran tinggi Andes (Amerika Selatan).

\section{Keragaan Usahatani Kentang di Kecamatan Ngablak}

Keragaan usahatani dimulai dari proses persiapan bibit dan pengolahan lahan untuk menggemburkan tanah. Bibit kentang di peroleh petani dari daerah $\mathrm{KBH}$ Kledung
Temanggung, Lembang, atau petani lain. Varietas kentang adalah Granola dan penanamannya ditimbun antara kedalaman 7$10 \mathrm{~cm}$. Pemeliharaan meliputi penyiangan, pendangiran, penguatan batang serta pemberantasan hama dan penyakit dengan penyemprotan pada umur 20-75 hari setelah tanam. Pemanenan kentang saat tanaman berumur antara 95-115 hari setelah tanam. Pasca panen berupa grading dan pengepakan serta di pasarkan langsung kepada tengkulak. Sejalan dengan Mailangkay et al (2012 : 163164), tahapan dalam budidaya kentang dimulai dari penggunaan bibit yang berkualitas, pengolahan tanah, penanaman, pemupukan, dan pengendalian hama penyakit tanaman.

\section{Biaya, Penerimaan, Pendapatan, dan Keuntungan}

Perhitungan biaya dalam penelitian ini adalah biaya yang dikeluarkan petani selama satu musim (4 bulan). Rata-rata biaya yang dikeluarkan petani untuk usahatani kentang adalah sebesar Rp 11.413.271,00. Besar rincian perhitungan rata-rata biaya yang dikeluarkan dalam usahatani kentang di Kecamatan Ngablak dapat dilihat pada Tabel 2.

Tabel 2. Rata-rata Biaya

\begin{tabular}{|c|c|}
\hline Uraian Biaya & Biaya $(\mathbf{R p})$ \\
\hline \multicolumn{2}{|l|}{ Penggunaan Saprodi } \\
\hline - bibit kentang & $6.124 .000,00$ \\
\hline - obat/pestisida & $884.847,00$ \\
\hline - $\quad$ pupuk & $1.423 .738,00$ \\
\hline - pengangkutan & $751.050,00$ \\
\hline Tenaga Kerja Luar & $1.627 .033,00$ \\
\hline \multicolumn{2}{|l|}{ Lain-Lain } \\
\hline - pajak tanah & $67.773,00$ \\
\hline - sewa lahan & $240.000,00$ \\
\hline $\begin{array}{l}\text { - bunga pinjaman } \\
\text { luar }\end{array}$ & $98.031,00$ \\
\hline \multicolumn{2}{|l|}{ Penyusunan Alat } \\
\hline - pacul & $6.247,00$ \\
\hline - semprotan/sprayer & $32.795,00$ \\
\hline - sabit & 526,00 \\
\hline - keranjang & $27.398,00$ \\
\hline - ember & $3.378,00$ \\
\hline - mulsa & $106.909,00$ \\
\hline - bambu lanjaran & $5.639,00$ \\
\hline - rafia & $13.739,00$ \\
\hline - gunting & 168,00 \\
\hline Jumlah & 11.413.271,00 \\
\hline
\end{tabular}

Sumber : Analisis Data Primer, 2016 
Besarnya rata-rata penerimaan dan rata-rata pendapatan dapat dilihat pada tabel 3.

Tabel 3. Rata-rata Luas Tanam, Produksi, Harga Penjualan Kentang, Penerimaan, Biaya, dan Pendapatan pada Usahatani Kentang

\begin{tabular}{lr}
\hline \multicolumn{1}{c}{ Uraian } & \multicolumn{1}{c}{ Jumlah } \\
\hline Luas Tanam $\left(\mathrm{m}^{2}\right)$ & 3.617 \\
Produksi $(\mathrm{Kg})$ & 3.181 \\
Harga Jual $(\mathrm{Rp})$ & $5.857,00$ \\
Penerimaan $(\mathrm{Rp})$ & $18.631 .117,00$ \\
Total Biaya $(\mathrm{Rp})$ & $11.413 .271,00$ \\
Pendapatan $(\mathrm{Rp})$ & $7.217 .846,00$ \\
\hline Sumber: Analisis Data Primer, 2016
\end{tabular}

Sumber : Analisis Data Primer, 2016

Rata-rata penerimaan usahatani kentang sebesar Rp 18.631.117,00. Disaat penelitian, terjadi penurunan harga jual kentang karena adanya panen raya kentang. Sedangkan untuk pendapatan usahatani kentang didapat dari pengurangan penerimaan dengan total biaya yang hasilnya sebesar Rp 7.217.846,00. Besarnya rata-rata keuntungan usahatani dapat dilihat pada Tabel 4.

Berdasarkan Tabel 4 dapat diketahui rata-rata biaya tenaga kerja keluarga sebesar Rp. 2.214.967,00 dan biaya untuk bunga modal sendiri sebesar Rp.175.808,00. Rata-rata keuntungan petani kentang adalah sebesar Rp. 4.827.071,00 sehingga usahatani kentang bisa dikatakan menguntungkan.
Tabel 4. Rata-rata Keuntungan Usahatani Kentang

\begin{tabular}{lr}
\hline \multicolumn{1}{c}{ Uraian } & \multicolumn{1}{c}{ Jumlah } \\
\hline Pendapatan (Rp). & $7.217 .846,00$ \\
Biaya tenaga kerja keluarga (Rp) & $2.214 .967,00$ \\
Bunga modal sendiri (Rp). & $175.808,00$ \\
Keuntungan (Rp). & $4.827 .071,00$ \\
\hline Sumber: Analisis Data Primer, 2016 &
\end{tabular}

Strategi Pengembangan Budidaya Kentang (Solanum Tuberosum l) di Kecamatan Ngablak Kabupaten Magelang

Matriks External Factor Evaluation memungkinkan para penyusun strategi untuk meringkas dan mengevaluasi ancaman dan peluang dari informasi ekonomi, sosial, budaya, demografis, lingkungan, politik, pemerintah, hukum, teknologi dan kompetitif. Matriks Evaluasi Faktor Internal (Internal Factor Evaluation-IFE Matrix), alat perumusan strategi yang digunakan untuk meringkas dan mengevaluasi kekuatan dan kelemahan utama dan area-area fungsional bisnis serta menjadi landasan untuk mengidentifikasi dan mengevaluasi hubungan diantara area tersebut (David, 2012 : 158-229). Berikut adalah matrik Internal Factor Evaluation dan matrik Eksternal Factor Evaluation pengembangan budidaya kentang di Kecamatan Ngablak.

Tabel 5. Matriks IFE Budidaya Kentang di Kecamatan Ngablak

\begin{tabular}{lccc}
\hline \multicolumn{1}{c}{ Faktor-Faktor Strategis Internal } & $\begin{array}{c}\text { Rataan } \\
\text { Bobot }\end{array}$ & Rating & Skor Bobot \\
\hline KEKUATAN & & & $\mathbf{0 , 4 5 2}$ \\
1. Sikap petani mudah menerima teknologi baru & 0,113 & 4 & 0,424 \\
2. Lingkungan yang cocok untuk penanaman kentang & 0,106 & 4 & 0,294 \\
3. Kentang yang dipasarkan berkualitas baik & 0,098 & 3 & 0,420 \\
4. Akses informasi petani ke pasar mudah & 0,105 & 4 & 0,118 \\
\hline KELEMAHAN & & & 0,092 \\
1. Keterbatasan modal & 0,118 & 1 & 0,097 \\
2. Kemampuan kognitif petani terbatas & 0,092 & 1 & 0,194 \\
3. Resiko budidaya tinggi & 0,097 & 1 & 0,178 \\
4. Produktivitas rendah & 0,097 & 2 & $\mathbf{0 , 0 8 5}$ \\
5. Penggunaan pestisida kimia yang berlebihan & 0,089 & 2 & $\mathbf{2 , 3 5 4}$ \\
6. Kurang berjalannya fungsi manajemen & 0,085 & 1 & $\mathbf{1 , 0 0 0}$ \\
\hline \multicolumn{1}{c}{ TOTAL } & & \\
\hline
\end{tabular}

Sumber : Analisis Data Primer, 2016 
Tabel 6. Matriks EFE Budidaya Kentang di Kecamatan Ngablak

\begin{tabular}{lccc}
\hline \multicolumn{1}{c}{ Faktor-Faktor Strategis Eksternal } & $\begin{array}{c}\text { Rataan } \\
\text { Bobot }\end{array}$ & Rating & Skor Bobot \\
\hline PELUANG & 0,112 & 3 & 0,336 \\
1. Sarana produksi mudah didapat & 0,112 & 4 & 0,448 \\
2. Penurunan suku bunga KUR & 0,091 & 2 & 0,182 \\
3. Tingginya permintaan kentang & 0,109 & 2 & 0,218 \\
4. Perkembangan teknologi & 0,111 & 3 & 0,333 \\
5. Meningkatnya pertumbuhan penduduk & 0,144 & 4 & $\mathbf{0 , 5 7 6}$ \\
6. Budaya gotong-royong masih berlaku & & & $\mathbf{0 , 4 5 2}$ \\
\hline ANCAMAN & 0,113 & 4 & 0,200 \\
1. Kenaikan harga sarana produksi & 0,100 & 2 & 0,216 \\
2. Kebijakan pemerintah yang kurang mendukung & 0,108 & 2 & $\mathbf{2 , 9 6 1}$ \\
3. Adanya pesaing usaha di bidang budidaya kentang & $\mathbf{1 , 0 0 0}$ & & \\
\hline \multicolumn{1}{c}{ TOTAL } & &
\end{tabular}

Sumber : Analisis Data Primer, 2016

Berdasarkan Tabel 5 hasil perhitungan matriks IFE dapat diketahui skor bobot total adalah 2,354, menandakan bahwa budidaya kentang di Kecamatan Ngablak Kabupaten Magelang pada posisi lemah secara internal dalam memanfaatkan kekuatan dan mengatasi kelemahan yang ada. Kekuatan utama adalah sikap petani mudah menerima teknologi baru. Kelemahan utama adalah kurang berjalannya fungsi manajemen.

Berdasarkan Tabel 6 hasil perhitungan matriks EFE dapat diketahui skor bobot total adalah 2,961, menandakan bahwa budidaya kentang di Kecamatan Ngablak Kabupaten Magelang pada posisi kuat secara eksternal atau memiliki respon yang baik dalam memanfaatkan peluang dan menghindari ancaman yang ada. Budaya gotong-royong masih berlaku menjadi peluang utama. Sedangkan ancaman utama adalah kenaikan harga sarana produksi.

SWOT Pearce dan Robinson Koordinat titik $X$ dan Y. Menurut Eva dan Dian (2011 : 79-82), analisis SWOT yang dikembangkan oleh Pearce dan Robinson didasarkan pada logika yang dapat memaksimalkan kekuatan dan peluang namun secara bersamaan dapat meminimalkan kelemahan dan ancaman. Berikut adalah hasil dari tahapan dalam SWOT Pearce dan Robinson.

Koordinat titik $X$ merupakan hasil dari pengurangan antara total nilai kekuatan dengan total nilai kelemahan dalam matriks IFE. Total nilai kekuatan $(1,590)$ dikurangi total nilai kelemahan $(0,764)$ sama dengan titik X $(0,826)$. Berdasarkan nilai tersebut koordinat titik $\mathrm{X}$ yaitu 0,826 dan titik koordinat tersebut berada pada sumbu positif atau sumbu Strenght(S).

Koordinat Titik $Y$ merupakan hasil dari pengurangan antara total nilai peluang dengan total nilai ancaman dalam matriks EFE. Total nilai peluang $(2,093)$ dikurangi total nilai ancaman $(0,868)$ sama dengan titik Y $(1,225)$. Berdasarkan nilai tersebut koordinat titik Y yaitu 1,225 dan titik koordinat tersebut berada pada sumbu positif atau sumbu Opportunity $(\mathrm{O})$.

Posisi titik $X$ dan $Y$ dalam diagram SWOT Pearce dan Robinson. Hasil perhitungan me- nunjukan bahwa koordinat titik $\mathrm{X}$ dan titik $\mathrm{Y}$ atau $(\mathrm{X}, \mathrm{Y})$ adalah $(0,826 ; 1,225)$. Titik $\mathrm{X}$ berada pada sumbu positif dan titik Y berada pada sumbu positif sehingga kedua titik tersebut bersumbu positif $(+,+)$ atau pada sumbu SO. Koordinat titik $\mathrm{X}$ dan titik $\mathrm{Y}$ tersebut dapat digambarkan dalam diagram SWOT Pearce dan Robinson untuk mengetahui posisi dalam pengembangan budidaya kentang di Kecamatan Ngablak Kabupaten Magelang. Berikut adalah gambar SWOT Pearce dan Robinson untuk pengembangan budidaya kentang di Kecamatan Ngablak Kabupaten Magelang.

Berdasarkan Gambar 1 Posisi titik X dan $\mathrm{Y}$ menunjukkan bahwa pengembangan budidaya kentang di Kecamatan Ngablak Kabupaten Magelang pada kuadran I. Pada kuadran ini, strategi yang dapat dilakukan adalah dengan memaksimalkan kekuatan serta memanfaatkan peluang perusahaan. Rekomendasi strategi yang diberikan adalah 


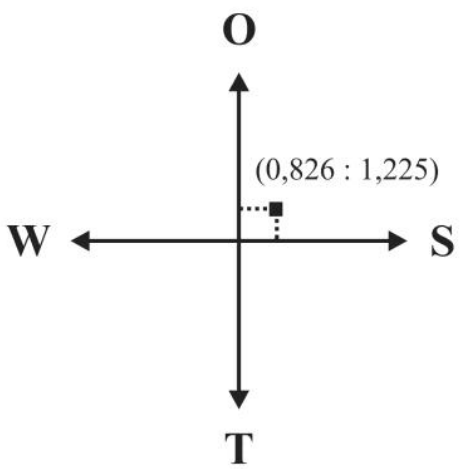

Gambar 1. Posisi Koordinat pada Diagram SWOT Pearce dan Robinson

strategi agresif, artinya organisasi dalam kondisi prima dan mantap sehingga sangat dimungkinkan untuk terus melakukan ekspansi, memperbesar pertumbuhan dan meraih kemajuan secara maksimal.

Berdasarakan analisis pada kuadran Matriks SWOT dengan pendekatan kuantitatif diketahui bahwa bahwa posisi strategi dalam pengembangan budidaya kentang di Kecamatan Ngablak Kabupaten Magelang berada pada kuadran I, sehingga dalam Matriks SWOT pendekatan kualitatif strategi yang dirumuskan alalah strategi SO. Perumusan strategi dengan menyesuaikan posisi perusahaan ini akan menghasilkan alternatif strategi yang sesuai dengan keadaan perusahaan. Strategi SO adalah strategi yang dihasilkan dari pencocokkan faktor kekuatan dengan faktor peluang. Rumusan alternatif strategi adalah seperti dalam Tabel 7.

Hasil pencocokan dari analisis matriks SWOT kualitatif menunjukan bahwa strategi yang dapat diterapkan dalam pengembangan budidaya kentang di Kecamatan Ngablak Kabupaten Magelang sesuai posisi kuadrannya adalah sebagai berikut :

Mempertahankan kualitas dan meningkatkan kuantitas hasil budidaya kentang dengan intensifikasi pertanian. Intensifikasi pertanian diharapkan mampu meningkatkan produktifitas hasil kentang di Kecamatan Ngablak. Menurut Setyawati (2009 : 21), intensifikasi pertanian adalah salah satu usaha untuk meningkatkan hasil pertanian dengan cara mengoptimalkan lahan perhatian yang sudah ada. Intensifikasi pertanian dapat dilakukan dengan beberapa cara yaitu pengolahan lahan atau tanah pertanian secara tepat, pengaturan irigasi atau saluran air, pemberian pupuk sesuai aturan, dan pemberantasan hama dengan baik. Pernyataan tersebut sejalan dengan Matson et al (1997 : 504), intensifikasi pertanian dengan menggunakan varietas tanaman unggul,

Tabel 7. Perumusan Strategi SO

\begin{tabular}{|c|c|}
\hline Eksternal & $\begin{array}{l}\text { KEKUATAN (Strengths) } \\
\text { 1. Sikap petani mudah menerima teknologi baru } \\
\text { 2. Lingkungan yang cocok untuk penanaman kentang } \\
\text { 3. Kentang yang dipasarkan berkualitas baik } \\
\text { 4. Akses informasi petani ke pasar mudah }\end{array}$ \\
\hline $\begin{array}{l}\text { PELUANG (Opportunities) } \\
\text { 1. Sarana produksi mudah didapat } \\
\text { 2. Penurunan suku bunga KUR } \\
\text { 3. Tingginya permintaan kentang } \\
\text { 4. Perkembangan teknologi } \\
\text { 5. Meningkatnya pertumbuhan } \\
\text { penduduk } \\
\text { 6. Budaya gotong-royong masih } \\
\text { berlaku }\end{array}$ & $\begin{array}{l}\text { Strategi SO } \\
\text { 1. Mempertahankan kualitas dan meningkatkan kuantitas hasil } \\
\text { budidaya kentang dengan intensifikasi pertanian } \\
\text { (S1,S2,S3,O1,O2,O3,O4,O5,O6) } \\
\text { 2. Memaksimalkan lahan penanaman kentang melalui sistem } \\
\text { budidaya monokultur dan rotasi tanam serta memanfaatkan } \\
\text { teknologi yang ada. } \\
\text { (S1,S2,O1,O2,O3,O4,O5,O6) } \\
\text { 3. Menjalin hubungan kerjasama pemasaran dengan lebih dari } \\
\text { satu tengkulak. } \\
\text { (S4,O2,O3,O5) }\end{array}$ \\
\hline
\end{tabular}

Sumber : Analisis Data Primer, 2016 
pemupukan, irigasi, dan pemberian pestisida yang tepat telah memberikan kontribusi besar terhadap peningkatan produksi pangan selama 50 tahun terakhir.

Memaksimalkan lahan penanaman kentang melalui sistem budidaya monokultur dan rotasi tanam serta memanfaatkan teknologi yang ada. Salah satu cara untuk meningkatkan produksi kentang adalah dengan memaksimalkan lahan penanaman kentang dengan sistem budidaya monokultur dan rotasi tanam dalam satu tahun. Menurut Santoso dalam Pujiharto (2015 : 223), pola tanam sistem monokultur merupakan usaha-tani dengan satu jenis tanaman dalam satu musim tanam dan menanam jenis tanaman yang sama atau berbeda pada musim tanam berikutnya. Pola tanam ini menggunakan rotasi yang bervariasi dalam satu tahun. Sedangkan produktivitas hasil kentang menurut Sutrisna et al (2005: 82), hasil kentang tiap petak seluas $60 \mathrm{~m}^{2}$ yang paling tinggi adalah pada pertanaman kentang dengan sistem monokultur, yaitu 143,8 kg, Sementara itu, hasil kentang yang ditanam tumpangsari dengan seledri 120,5 $\mathrm{kg}$ dan yang ditanam tumpang-sari dengan bawang daun $99,0 \mathrm{~kg}$.

$$
\text { Menjalin hubungan kerjasama }
$$

pemasaran dengan lebih dari satu tengkulak. Melalui strategi menjalin hubungan kerjasama pemasaran dengan lebih dari satu tengkulak dapat meningkatkan perkembangan budidaya kentang di Kecamatan Ngablak Kabupaten Magelang karena akan memudahkan petani dalam mencari harga bersaing dalam penjualan kentang. Hubungan kerjasama ini juga digunakan untuk memanfaatkan peluang dari permintaan kentang yang tinggi sehingga kentang yang dihasilkan dapat langsung terjual untuk memenuhi permintaan kentang baik di Kecamatan Ngablak atau di luar Kecamatan Ngablak.

Matriks Perencanaan Strategi Kuantitatif (Quantitative Strategic Planning Matrix$Q S P M)$ digunakan untuk mengevaluasi dan memilih strategi terbaik yang paling cocok dengan lingkungan eksternal dan internal. Alternatif strategi yang memiliki nilai total terbesar pada QSPM merupakan strategi yang paling baik. Prioritas strategi dengan QSPM sebagai berikut:

Tabel 8. Matrik Quantitative Strategic Planning (QSPM).

\begin{tabular}{|c|c|c|c|c|c|c|c|}
\hline \multirow{3}{*}{ Faktor-faktor kunci } & \multirow{3}{*}{ Bobot } & \multicolumn{6}{|c|}{ Alternatif Strategi } \\
\hline & & \multicolumn{2}{|c|}{ Strategi 1} & \multicolumn{2}{|c|}{ Strategi 2} & \multicolumn{2}{|c|}{ Strategi 3} \\
\hline & & $\mathbf{A S}$ & TAS & $\mathbf{A S}$ & TAS & $\mathbf{A S}$ & TAS \\
\hline \multicolumn{8}{|l|}{ Faktor Internal } \\
\hline Kekuatan & & & & & & & \\
\hline Sikap petani mudah menerima teknologi baru & 0,113 & 3 & 0,339 & 2 & 0,226 & 4 & 0,452 \\
\hline $\begin{array}{l}\text { Lingkungan yang cocok untuk penanaman } \\
\text { kentang }\end{array}$ & 0,106 & 4 & 0,424 & 2 & 0,212 & 3 & 0,318 \\
\hline Kentang yang dipasarkan berkualitas baik & 0,098 & 3 & 0,294 & 2 & 0,196 & 3 & 0,294 \\
\hline $\begin{array}{l}\text { Petani menjalin kerjasama dengan lebih dari satu } \\
\text { tengkulak }\end{array}$ & 0,105 & 2 & 0,210 & 1 & 0,105 & 3 & 0,315 \\
\hline \multicolumn{8}{|l|}{ Kelemahan } \\
\hline Keterbatasan modal & 0,118 & 2 & 0,236 & 3 & 0,354 & 4 & 0,472 \\
\hline Kemampuan petani terbatas & 0,092 & 4 & 0,368 & 3 & 0,276 & 2 & 0,184 \\
\hline Resiko budidaya tinggi & 0,097 & 3 & 0,291 & 4 & 0,388 & 2 & 0,194 \\
\hline Produktivitas rendah & 0,097 & 4 & 0,388 & 3 & 0,291 & 2 & 0,194 \\
\hline Penggunaan pestisida kimia yang berlebihan & 0,089 & 3 & 0,267 & 4 & 0,356 & 2 & 0,178 \\
\hline Kurang berjalannya fungsi manajemen & 0,085 & 4 & 0,340 & 3 & 0,255 & 2 & 0,170 \\
\hline Total Bobot & 1,000 & & & & & & \\
\hline \multicolumn{8}{|l|}{ Faktor Eksternal } \\
\hline Peluang & & & & & & & \\
\hline Sarana produksi mudah didapat & 0,112 & 4 & 0,448 & 3 & 0,336 & 2 & 0,224 \\
\hline Penurunan suku bunga KUR & 0,112 & 4 & 0,448 & 3 & 0,336 & 2 & 0,224 \\
\hline Tingginya permintaan kentang & 0,091 & 4 & 0,364 & 3 & 0,273 & 2 & 0,182 \\
\hline Perkembangan teknologi & 0,109 & 4 & 0,436 & 3 & 0,327 & 2 & 0,218 \\
\hline Meningkatnya pertumbuhan penduduk & 0,111 & 4 & 0,444 & 3 & 0,333 & 2 & 0,222 \\
\hline
\end{tabular}




\begin{tabular}{|c|c|c|c|c|c|c|c|}
\hline $\begin{array}{c}\text { Budaya gotong-royong masih berlaku } \\
\text { Ancaman }\end{array}$ & 0,144 & 4 & 0,576 & 3 & 0,432 & 2 & 0,288 \\
\hline Kenaikan harga sarana produksi & 0,113 & 2 & 0,226 & 3 & 0,339 & 4 & 0,452 \\
\hline Kebijakan pemerintah yang kurang mendukung & 0,100 & 4 & 0,400 & 3 & 0,300 & 2 & 0,200 \\
\hline $\begin{array}{l}\text { Adanya pesaing usaha di bidang budidaya } \\
\text { kentang }\end{array}$ & 0,108 & 3 & 0,324 & 2 & 0,216 & 4 & 0,432 \\
\hline Total Bobot & 1,000 & & & & & & \\
\hline Jumlah Skor Daya Tarik Total (TAS) & & & 6,823 & & 5,551 & & $\mathbf{5 , 2 1 3}$ \\
\hline
\end{tabular}

Sumber: Data Primer 2016

Keterangan Tabel :

Strategi $1=$ Mempertahankan kualitas dan meningkatkan kuantitas hasil budidaya kentang dengan intensifikasi pertanian.

Strategi 2 = Memaksimalkan lahan penanaman kentang melalui sistem budidaya monokultur dan rotasi tanam serta memanfaatkan teknologi yang ada.

Strategi $3=$ Menjalin hubungan kerjasama pemasaran dengan lebih dari satu tengkulak.

Berdasarkan hasil perhitungan Tabel 8 tersebut menunjukkan bahwa strategi yang memungkinkan untuk diterapkan adalah mempertahankan kualitas dan meningkatkan kuantitas hasil budidaya kentang dengan intensifikasi pertanian. Pemilihan strategi tersebut menjadi prioritas utama untuk dijalankan didasarkan pada jumlah nilai Total Attractiveness Score (TAS) tertinggi yaitu 6,823. Prioritas strategi kedua adalah memaksimalkan lahan penanaman kentang melalui sistem budidaya monokultur dan rotasi tanam serta memanfaatkan teknologi yang ada. Pemilihan strategi tersebut menjadi prioritas kedua untuk dijalankan didasarkan pada jumlah nilai Total Attractiveness Score (TAS) yang menempati posisi kedua (5,551). Menjalin hubungan kerjasama pemasaran dengan lebih dari satu tengkulak. Merupakan prioritas strategi ketiga untuk dijalankan didasarkan pada jumlah nilai Total Attractiveness Score (TAS) yang menempati posisi ketiga $(5,213)$.

\section{KESIMPULAN DAN SARAN}

\section{Kesimpulan}

Berdasarkan pada penelitian dapat disimpulkan sebagai berikut:

1. Besarnya rata-rata biaya produksi budidaya kentang dalam satu musim tanam (4 bulan) adalah sebesar Rp.11.413.271,00, sedangkan untuk rata-rata penerimaan usahatani sebesar Rp.18.631.117,00, sehingga diperoleh rata-rata pendapatan petani sebesar Rp.7.217.846,00. Rata-rata keuntungan petani kentang adalah Rp.4.827.071,00, sehingga usahatani budidaya kentang dapat dikatakan menguntungkan untuk dijalankan.

2. Faktor-faktor internal yang menjadi kekuatan adalah sikap petani mudah menerima teknologi baru, lingkungan yang cocok untuk penanaman kentang,kentang yang dipasarkan berkualitas baik, dan dan akses informasi petani ke pasar mudah. Faktor-faktor internal yang menjadi kelemahan adalah keterbatasan modal, kemampuan kognitif petani terbatas, resiko budidaya tinggi, produktivitas rendah, penggunaan pestisida kimia yang berlebihan, dan kurang jalannya fungsi manajemen. Faktor-faktor eksternal yang menjadi peluang adalah sarana produksi mudah didapat, penurunan suku bunga KUR, tingginya permintaan kentang, perkembangan teknologi, meningkatnya pertumbuhan penduduk, dan budaya gotong royong masih berlaku. Faktorfaktor eksternal yang menjadi ancaman adalah kenaikan harga sarana produksi, kebijakan pemerintah yang kurang mendukung, dan adanya pesaing usaha di bidang budidaya kentang.

3. Alternatif strategi yang baik untuk diterapkan dalam pengembangan budidaya kentang (Solanum Tuberosum L) di Kecamatan Ngablak Kabupaten Magelang adalah mempertahankan kualitas dan meningkatkan kuantitas hasil budidaya kentang dengan intensifikasi pertanian, memaksimalkan lahan penanaman kentang melalui sistem budidaya monokultur dan rotasi tanam serta memanfaatkan teknologi yang ada, dan menjalin hubungan kerjasama 
pemasaran dengan lebih dari satu tengkulak.

4. Prioritas strategi yang baik atau utama untuk diterapkan dalam pengembangan budidaya kentang (Solanum Tuberosum L) di Kecamatan Ngablak Kabupaten Magelang adalah mempertahankan kualitas dan meningkatkan kuantitas hasil budidaya kentang dengan intensifikasi pertanian.

\section{Saran}

Saran yang dapat diberikan adalah sebagai berikut:

1. Sebaiknya petani kentang menerapkan strategi prioritas yang terpilih yaitu mempertahankan kualitas dan berusaha meningkatkan kuantitas hasil budidaya kentang dengan intensifikasi pertanian.

2. Sebaiknya Balai Penyuluh Pertanian dan Kehutanan (BPPK) melakukan pembinaan dan penyuluhan tentang intensifikasi pertanian untuk menambah wawasan dan pengetahuan sehingga intensifikasi pertanian dapat diterapkan dengan baik oleh petani dalam budidaya kentang.

3. Sebaiknya pihak petani kentang dan pemerintah Kecamatan Ngablak khususnya Balai Penyuluhan Pertanian dan Kehutanan (BPPK) Kecamatan Ngablak Kabupaten Magelang dalam menjalankan kegiatan usa hatani atau menyusun program dapat mempertimbangkan kekuatan, kelemahan, peluang dan ancaman utama serta beberapa alternatif strategi.

\section{DAFTAR PUSTAKA}

Baihaqi, A., Moch. N., A. L. Abadi. 2013. Teknik Aplikasi Trichoderma Sp. Terhadap Pertumbuhan Dan Hasil Tanaman Kentang (Solanum Tuberosum L.). Jurnal Produksi Tanaman Vol. 1 No. 3. ISSN : 2338-3976.

BPS Kabupaten Magelang. 2014. Luas Panen dan Produksi Tanaman Sayur-sayuran menurut Kecamatan, 20112014. http://magelangkab.bps.go.id /Subjek/view/id/55 \#subjekViewTab3. Di akses Tanggal 1 Oktober 2015.

BPS Provinsi Jawa Tengah. 2013. Statistik Pertanian Hortikultura Jawa Tengah
Tahun 2010-2014. Badan Pusat Statistik Provinsi Jawa tengah. Semarang

David, F. R. 2012. Manajemen Strategi Konsep. Penerjemah Dono Sunardi. Salemba Empat. Jakarta.

Eva, F. dan Dian, D. 2011. Identifikasi Faktor Utama Pondok Pesantren Dalam Pengembangana Hutan Rakyat. Jurnal Analisis Kebijakan Kehutanan 8(1): 7779.

Khuranas, M. P. 2006. Indian potato exports an overview. Potato Journal 33(1-2): 1-10.

Kloosterman, B. et al. 2013. Naturally occurring allele diversity allows potato cultivation in northern latitudes. Nature 495(7440): 246-250.

Mailangkay, B. H. Paulus. Johannes, E. X. R. 2012.Growth And Production Of Two Varieties Of Potato (Solanum Tuberosum L.).) On Two Level Altitudes. Eugenia 18(2):161-170.

Matson, P. A. Parton, W. J. Power, A. G. Swift, M. J. 1997. Agricultural intensification and ecosystem properties. Science 277(5325): 504-509.

Pujiharto, P. 2015. Optimalisasi Berbagai Pola Tanam Monokultur Pada Tanaman Pangan Semusim Di Wilayah Kecamatan Kembaran, Kabupaten Banyumas. In Proceeding Seminar LPPM UMP. ISBN: 978-602-14930-3-8:222-227.

Renstra Dirjen Hortikultura. 2015. Rencana Strategis Direktorat Jendral Hortikultura Tahun 20152019.Kementerian Pertanian Dirjen Hortikultura Republik Indonesia

Sensus Pertanian. 2013. Laporan Hasil Sensus Pertanian 2013 (pencacahan Lengkap). Badan Pusat Statistik. Jakarta

Setiadi. 2009. Budidaya Kentang. Penebar Swadaya. Jakarta

Setyawati, E. Ayu. 2012.Strategi Pengembangan Agribisnis Belimbing Dewa Di Kota Depok. Skripsi. Fakultas Pertanian Universitas Sebelas Maret. Surakarta. 
Mahkruf J. P., Mohd. Harisudin, Aulia Q. : Strategi Pengembangan Budidaya Kentang ...

Singarimbun, M. 1995. Metode Penelitian Survei. LP3ES. Jakarta

Surakhmad, W. 2006. Pengantar Penelitian Ilmiah Dasar, Metode dan Teknik Edisi Revisi, Disempurnakan. Penerbit Tarsito. Bandung.
Sutrisna, N. Surdianto, Y. 2016. Kajian Formula Pupuk NPK Pada Pertanaman Kentang Lahan Dataran Tinggi di Lembang Jawa Barat. Jurnal Hortikultura24(2): 124-132. 